\title{
BMJ Open Effect of visit-to-visit blood pressure variability on cardiovascular events in populations with different body mass indexes: a prospective cohort study
}

\author{
Haojia Chen (D) , ${ }^{1,2}$ Youren Chen (D) , ${ }^{3}$ Weiqiang Wu, ${ }^{3}$ Jianhuan Huang, ${ }^{2,3}$ \\ Zekai Chen, ${ }^{2,3}$ Zhichao Chen, ${ }^{3}$ Xiuzhu Yan, ${ }^{4}$ Shouling Wu ${ }^{5}$
}

To cite: Chen $\mathrm{H}$, Chen Y, Wu W, et al. Effect of visit-to-visit blood pressure variability on cardiovascular events in populations with different body mass indexes: a prospective cohort study. BMJ Open 2020;10:e035836. doi:10.1136/ bmjopen-2019-035836

- Prepublication history for this paper is available online. To view these files, please visit the journal online (http://dx.doi. org/10.1136/bmjopen-2019035836).

Received 21 November 2019 Revised 27 July 2020 Accepted 06 August 2020
Check for updates

(C) Author(s) (or their employer(s)) 2020. Re-use permitted under CC BY-NC. No commercial re-use. See rights and permissions. Published by BMJ.

For numbered affiliations see end of article.

\section{Correspondence to}

Dr Youren Chen;

13902779840@139.com and

Professor Shouling Wu;

drwus|@163.com

\section{ABSTRACT}

Objective This study was performed to explore the effects of visit-to-visit blood pressure variability (BPV) on cardiovascular events (CVEs) in people with various body mass indexes (BMls).

Design Prospective cohort study.

Setting The average real variability of systolic blood pressure ( $\left(\mathrm{RV}_{\mathrm{SBP}}\right.$ ) was the indicator for visit-to-visit BPV. The participants were divided into three groups: normal weight, overweight and obesity. We further divided these groups into four subgroups based on the ARV $\mathrm{SBP}$. A Cox regression model was used to calculate the HRs of the $A_{\text {ARV }}$ on CVEs in the same and different BMI groups. Additionally, a competitive risk model was used to calculate the HRs of the ARV ${ }_{\text {SBP }}$ on CVEs in the same BMI group.

Participants In total, 41043 individuals met the inclusion criteria (no historical CVEs or tumours, no incidence of CVEs or tumours and no death during the four examinations) and had complete systolic blood pressure and BMl data.

Results A total of 868 CVES occurred. The cumulative incidence of CVEs increased as ARV SBP rose in both the normal weight and overweight groups. In same BMI groups, the risk of CVEs significantly increased as ARV ${ }_{\text {SBP }}$ increased only in the normal weight group (highest quartiles of $\mathrm{ARV}_{\mathrm{SBP}}$ : $\left.\mathrm{HR}(95 \% \mathrm{Cl}) 2.20(1.46-3.31)\right)$. In the different BMl groups, the risk of CVEs in the ARV subgroup in each BMl group was higher than that the least quintile of $A R V_{S B P}$ in the normal weight group (highest quartiles of ARV ${ }_{S B P}$ in obesity: HR $(95 \% \mathrm{Cl}) 2.28$ $(1.47-3.55))$. The result of the competitive risk model did not change.

Conclusions $\mathrm{As} B M l$ and $A R V_{S B P}$ increase, the risk of CVEs increases. However, the risk of visit-to-visit BPV on CVEs varies in different BMl groups, especially in people of normal weight.

Trial registration number CHICTR-TNC1100 1489.

\section{INTRODUCTION}

During the past 30 years, the incidence of overweight or obesity has doubled worldwide. The situation of overweight or obesity is more severe in China, where the incidence has increased by two to three times. ${ }^{12}$ The body

\section{Strengths and limitations of this study}

- This is the first study to explore the effects of visitto-visit blood pressure variability on cardiovascular events in people with various body mass indexes.

- This study was based on the Kailuan Study, which was a prospective, population-based cohort study with a large sample size.

- Taking into account the effect of death in the Cox risk model, a competitive risk model was adopted for a second risk assessment.

- The research population was limited to Kailuan Group employees, most of whom lived in communities in North China.

- The blood pressure measurements were only obtained from physical examination data, without collection of information on home blood pressure or multiple blood pressure measurements in 1 year.

mass index (BMI) is a convenient indicator that is widely used in research of overweight or obesity. Previous studies have shown that the BMI is closely related to visit-to-visit blood pressure variability (BPV). Li et $a l^{3}$ found that the visit-to-visit BPV increased by 0.029 units with every 1-unit increase in the BMI. Our previous study ${ }^{4}$ showed that the average real variability of systolic blood pressure $\left(\mathrm{ARV}_{\mathrm{SBP}}\right)$ increased by 0.077 units with every 1-unit increase in the BMI. Another previous study ${ }^{5}$ showed that the relationship between the BMI and $\mathrm{ARV}_{\mathrm{SBP}}$ may involve the release of inflammatory factors by adipose tissue, resulting in higher arterial stiffness and thus higher BPV.

Cardiovascular events (CVEs) are one of the main causes of death, and approximately 18 million people worldwide die of CVEs annually. ${ }^{6}$ Previous studies have shown that a high BMI and increased visit-to-visit BPV are risk factors for CVEs. ${ }^{7-9} \mathrm{~A}$ meta-analysis showed that for each $5 \mathrm{~kg} / \mathrm{m}^{2}$ increase in the BMI, the risk of coronary heart disease and 
stroke increased by 1.27 and 1.18 times, respectively. ${ }^{7}$ Another meta-analysis showed that the risk of stroke increased by 1.15 times, coronary heart disease by 1.10 times and CVEs by 1.18 times as the visit-to-visit BPV of systolic blood pressure (SBP) increases. ${ }^{8}$

A higher BMI and higher visit-to-visit BPV are associated with a higher risk of CVEs. To the best of our knowledge, however, no studies have focused on the effect of visit-tovisit BPV on CVEs in different BMI groups. The Kailuan Study was a community-based study on the assessment and intervention of risk factors for CVEs. The participants in that study underwent physical examinations every 2 years beginning in 2006, including measurement of blood pressure (BP), height and weight. Annual checks and information on CVEs and death were also recorded. In the present study, we examined the effect of visit-to-visit BPV on CVEs in different BMI groups using the Kailuan Study cohort.

\section{PARTICIPANTS AND METHODS}

\section{Patient and public involvement}

Patients and the public were not involved in the design of this study.

\section{Study participants}

This prospective cohort study began in 2006-2007. Staff members from Kailuan Corporation in China who were working in or retired from the Kailuan Group participated in this study. All staff members were $>18$ years of age and were from geographical locations throughout China. Most of the participants were from the northeast area of China (Beijing, Heibei and so on). Therefore, this study has certain guiding significance for the prevention of CVEs among North China's population. Participants with complete SBP and BMI data obtained at the first medical examination and with no history of CVEs or tumours were included. Medical doctors were in charge of the first to fourth medical examinations, which were performed every 2 years. We excluded individuals with any missing data on SBP or the incidence of CVEs, tumours or death during the period in which the four medical examinations were performed.

\section{Data collection}

Details of the epidemiological investigations and anthropometry index measurements were previously reported. ${ }^{10} 11$ Questionnaires were personally administered by the research doctors to collect information on the participants' sociodemographic status (sex, age, education, economic status), lifestyle habits (alcohol consumption, smoking status, physical exercise) and personal health history (hypertension, diabetes, CVEs). Smoking was defined as having smoked an average of at least one cigarette per day during the past year. Drinking was defined as an average daily alcohol consumption of more than $100 \mathrm{~mL}$ (alcohol concentration of $>50 \% \mathrm{v} / \mathrm{v}$ ) during the past 1 year and lasting for more than 1 year.
Physical exercise was defined as engaging in exercise at least three times weekly for more than $30 \mathrm{~min}$ each time. The information about historical CVEs was through querying and/or searching inpatient diagnoses and endpoint records of the participants.

BP measurements were performed as follows. The participants were strictly prohibited from drinking alcohol, drinking coffee, or smoking for at least $30 \mathrm{~min}$. BP was measured after they had sat quietly for $15 \mathrm{~min}$. Each participant stretched out his or her bare right upper arm at $45^{\circ}$ and ensured that the elbow lay on the surface of the desk at the level of the heart. Suitable cuffs were wound around the participant's upper arm and tightened close to the skin with proper tension. The cuff size varied by the upper arm circumference as follows: $12 \times 22 \mathrm{~cm}$ cuff for a 22 to $26 \mathrm{~cm}$ arm circumference, $16 \times 30 \mathrm{~cm}$ cuff for 27 to $34 \mathrm{~cm}$ circumference, $16 \times 36 \mathrm{~cm}$ cuff for 35 to $44 \mathrm{~cm}$ circumference and $16 \times 42 \mathrm{~cm}$ cuff for 45 to $52 \mathrm{~cm}$ circumference. The upper edge of the cuff was positioned approximately $2.5 \mathrm{~cm}$ above the chelidon, and the centre was positioned immediately above the brachial artery. An adjusted mercury sphygmomanometer was used during the first four physical examinations to measure the BP of the right brachial artery. Phase 1 Korotkoff sounds were chosen for the SBP reading, and phase 5 Korotkoff sounds were chosen for the diastolic BP reading. An electronic sphygmomanometer (HEM-8102A; Omron, Daling, China) was used to measure the $\mathrm{BP}$ of the right brachial artery during the fifth physical examination. The average of three BP readings obtained three times at 1 min intervals was recorded as the final $\mathrm{BP}$ of each participant for each physical examination.

For height and weight measurements (accurate to $0.1 \mathrm{~cm}$ and $0.1 \mathrm{~kg}$, respectively), the participants stood barefoot in thin garments and no hat, and their height and weight were measured using a calibrated RGZ-120 scale from 7:30 Am to 9:00 Am. The BMI was calculated as weight divided by height squared $\left(\mathrm{kg} / \mathrm{m}^{2}\right)$.

\section{Biochemical measurements}

Blood samples were taken from the antecubital vein of the participants after an overnight fast and collected in EDTA tubes. The serum supernatant was measured within 4 hours. The hexokinase method was used to measure the fasting blood glucose concentration. The total cholesterol and high-density lipoprotein concentrations were enzymatically measured (Mind Bioengineering, Shanghai, China). A high-sensitivity nephelometric assay (Cias Latex CRP-H; Kanto Chemical, Tokyo, Japan) was used to measure the high-sensitivity $\mathrm{C}$ reactive protein concentration. All biochemical parameters were measured with an automatic biochemical analyzer (Hitachi 747; Hitachi, Tokyo, Japan).

\section{Relevant definitions}

Measurement of visit-to-visit $\mathrm{BPV}^{12}{ }^{13}$ includes the SD of $\mathrm{BP}$, the coefficient of variation, the variability uncorrelated with mean $\mathrm{BP}$ and the average real variability. 
BMI $\geq 28.0$

BMI $<24.0$

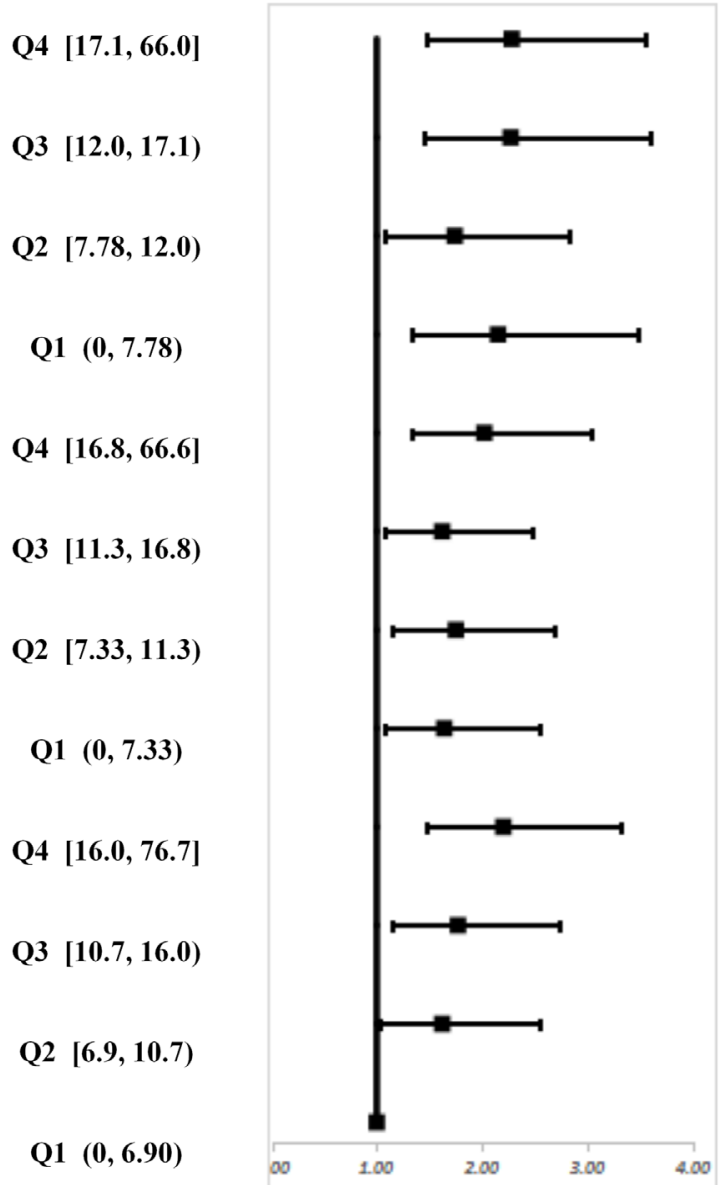

$2.28(1.47-3.55)$

2.27(1.44-3.58)

1.74(1.07-2.83)

2.15(1.34-3.47)

2.02(1.34-3.02)

$1.62(1.07-2.46)$

$1.75(1.15-2.67)$

1.64(1.07-2.53)

$2.20(1.46-3.31)$

1.77(1.15-2.72)

$1.62(1.03-2.53)$

1

Figure 1 Cox analysis forest plot for the effect of $A R V_{S B P}$ on CVEs in different BMI groups. *Adjusted for sex, age, total cholesterol level, heart rate, high-sensitivity $C$ reactive protein level, high-density lipoprotein level, sbp1, smoking, salt intake, drinking, exercise and diabetes mellitus. ARVSBP, average real variability of systolic blood pressure; BMI, body mass index; CVEs, cardiovascular events; sbp1, systolic blood pressure of the first physical examination.

There has been uncertainty on which indicator to adopt for BPV. Previous studies mostly used SD of BP. ${ }^{14}$ However, $\mathrm{SD}$ was not able to distinguish systematic changes in BP over time from true variation in $\mathrm{BP}^{15}{ }^{16}$ Some studies pointed out that the root-mean-square error can better show the authenticity of BPV. However, this indicator was not statistically significant to the incidence but the mortality of CVEs. ${ }^{13}$ And the subjects of most studies were elderly. Meanwhile, some studies hold different points of view that the average real variability can more effectively predict the damage to the target organ and requires no time sequence of BP readings. ${ }^{17-20}$ In addition, previous studies on the correlation between visit-to-visit BPV and BMI only have the indicator of average real variability. As the result of the above, average real variability was chosen as the indicator for visit-to-visit BPV in this study. The formula ${ }^{18-20}$ for calculating $A R V_{\text {SBP }}$ was as follows: $\mathrm{ARV}_{\mathrm{SBP}}$ $=(|s b p 2-\operatorname{sbp} 1|+\mid s b p 3-$ sbp2|+|sbp4-sbp3I)/3, where sbp1, sbp2, sbp3 and sbp4 represent SBP of the first to fourth physical examinations, respectively. Previous studies have illustrated that systolic BPV can more effectively predict CVEs than diastolic BPV. ${ }^{21} 22$ Thus, we focused on systolic
BPV rather than diastolic BPV in this study. For participants undergoing antihypertensive therapy, $10 \mathrm{~mm} \mathrm{Hg}$ was added to the SBP and $5 \mathrm{~mm} \mathrm{Hg}$ was added to the diastolic BP. ${ }^{23} 24$

\section{Outcomes}

The 2012 medical examination was considered the start of the follow-up period, and the last follow-up date was 31 December 2016; this was the last date on which new CVEs and death were recorded. CVEs included stroke (haemorrhagic stroke and ischaemic stroke) and myocardial infarction. Every year, trained doctors referred to the inpatient diagnoses and endpoint records of the patients in the hospitals that were affiliated with the Kailuan Group and the municipal Medicare-appointed hospitals. All diagnoses were confirmed by professional physicians on the basis of the inpatient medical records. The incidence of death was also obtained from provincial population statistics offices or medical records of medical insurance companies annually. The diagnosis standard of stroke and myocardial infarction was based on the guidelines issued by the American Heart Association and European 
Table 1 General information of the study population

\begin{tabular}{|c|c|c|c|c|c|c|}
\hline Group & $\begin{array}{l}B M I<24.0 \\
(n=16181)\end{array}$ & $\begin{array}{l}24.0 \leq B M I<28.0 \\
(n=17202)\end{array}$ & $\begin{array}{l}\mathrm{BMI} \geq 28.0 \\
(\mathrm{n}=7591)\end{array}$ & $\begin{array}{l}\text { Total } \\
(n=41043)\end{array}$ & $\begin{array}{l}\text { Corresponding } \\
\text { tests }\end{array}$ & $P$ trend \\
\hline Man, \% & 11489 (70.8) & $13749(79.9)$ & $5993(78.9)$ & 31231 (76.1) & $\mathrm{F}$ test & $<0.0001$ \\
\hline Age, year & $46.8 \pm 11.9$ & $48.5 \pm 10.9$ & $47.4 \pm 11.2$ & $47.6 \pm 11.4$ & $\mathrm{~F}$ test & $<0.0001$ \\
\hline $\mathrm{sbp} 1, \mathrm{~mm} \mathrm{Hg}$ & $122 \pm 18.5$ & $130 \pm 20.0$ & $136 \pm 20.6$ & $128 \pm 20.2$ & $\mathrm{~F}$ test & $<0.0001$ \\
\hline $\mathrm{sbp} 2, \mathrm{~mm} \mathrm{Hg}$ & $124 \pm 18.9$ & $131 \pm 19.5$ & $137 \pm 20.2$ & $129 \pm 20.0$ & $\mathrm{~F}$ test & $<0.0001$ \\
\hline sbp3, mm Hg & $125 \pm 18.6$ & $133 \pm 19.1$ & $137 \pm 19.5$ & $131 \pm 20.0$ & $\mathrm{~F}$ test & $<0.0001$ \\
\hline $\mathrm{sbp} 4, \mathrm{~mm} \mathrm{Hg}$ & $126 \pm 19.1$ & $133 \pm 19.3$ & $137 \pm 19.3$ & $131 \pm 19.7$ & $\mathrm{~F}$ test & $<0.0001$ \\
\hline $\mathrm{ARV}_{\mathrm{SBP}}, \mathrm{mm} \mathrm{Hg}$ & $10.8(9.09)$ & $11.3(9.34)$ & $12.0(9.32)$ & $11.2(9.34)$ & $\mathrm{F}$ test & $<0.0001$ \\
\hline Smoking, \% & $4925(30.3)$ & $5241(30.4)$ & $2138(28.1)$ & $12304(30.0)$ & $\chi^{2}$ test & 0.001 \\
\hline Drinking, $\%$ & $2762(17.0)$ & $3122(18.1)$ & $1158(15.2)$ & $7042(17.2)$ & $\chi^{2}$ test & $<0.0001$ \\
\hline Snorer, \% & $1396(8.6)$ & $2316(13.5)$ & $1486(19.6)$ & $5198(12.7)$ & $\chi^{2}$ test & $<0.0001$ \\
\hline Salt intake, \% & $1486(9.2)$ & $1813(10.5)$ & $891(11.7)$ & $4190(10.2)$ & $\chi^{2}$ test & $<0.0001$ \\
\hline Physical exercise, \% & $2043(12.6)$ & $2287(13.3)$ & $1006(13.2)$ & $5336(13.0)$ & $\chi^{2}$ test & 0.133 \\
\hline HDL & $1.60 \pm 0.40$ & $1.53 \pm 0.39$ & $1.50 \pm 0.38$ & $1.55 \pm 0.39$ & $\mathrm{~F}$ test & $<0.0001$ \\
\hline $\mathrm{TC}, \mathrm{mmol} / \mathrm{L}$ & $4.81 \pm 1.08$ & $4.96 \pm 1.20$ & $5.00 \pm 1.15$ & $4.91 \pm 1.14$ & $\mathrm{~F}$ test & $<0.0001$ \\
\hline Heart rate, beat/min & $73.4 \pm 10.3$ & $73.3 \pm 9.62$ & $74.0 \pm 9.64$ & $73.5 \pm 9.90$ & $\mathrm{~F}$ test & $<0.0001$ \\
\hline Hypertension, \% & $4023(24.8)$ & $7043(40.9)$ & $4114(54.2)$ & $15180(37.0)$ & $\chi^{2}$ test & $<0.0001$ \\
\hline Antihypertensive therapy, \% & $635(3.9)$ & $1496(8.7)$ & $1006(13.2)$ & 3137 (7.6) & $\chi^{2}$ test & $<0.0001$ \\
\hline Diabetes mellitus, \% & $742(4.6)$ & $1444(8.4)$ & $839(11.0)$ & $3025(7.4)$ & $\chi^{2}$ test & $<0.0001$ \\
\hline hs-CRP, log 10 & $-0.29 \pm 0.72$ & $-0.11 \pm 0.65$ & $0.05 \pm 0.60$ & $-0.15 \pm 0.68$ & $\mathrm{~F}$ test & $<0.0001$ \\
\hline
\end{tabular}

$\mathrm{ARV}_{\mathrm{SBP}}$, average real variability of systolic blood pressure; BMI, body mass index; HDL, high-density lipoprotein; hs-CRP, high-sensitivity $\mathrm{C}$ reactive protein; sbp1, sbp2, sbp3 and sbp4, systolic blood pressure of the first to fourth physical examinations; TC, total cholesterol.

Society of Cardiology, and the diagnosis standard varied according to the updates of the guidelines.

\section{Statistical methods}

We calculated the interaction between the BMI grouping variables and the $A R V_{S B P}$ grouping variables ( $p$ for interaction $<0.05$ ). Therefore, a stratified analysis by BMI was used for $\mathrm{ARV}_{\mathrm{SBP}}$ in this study. According to the criteria for defining obesity in China, the participants' body weight was divided into three groups by the BMI as follows: ${ }^{25}$ normal weight (BMI of $<24.0 \mathrm{~kg} / \mathrm{m}^{2}$ ), overweight (BMI of $\geq 24 \mathrm{to}<28.0 \mathrm{~kg} / \mathrm{m}^{2}$ ) and obesity (BMI of $\geq 28.0 \mathrm{~kg} /$ $\left.\mathrm{m}^{2}\right)$. Because there was no normal range of $\mathrm{ARV}_{\mathrm{SBP}}$ and it had a skewed distribution, $\mathrm{ARV}_{\mathrm{SBP}}$ of each BMI group was divided into four quartiles (Q1, Q2, Q3 and Q4) (figure 1). SAS 9.4 (SAS Institute, Cary, North Carolina, USA) was used for the data analysis. Continuous variables are presented as mean $\pm \mathrm{SD}$, and we used single-factor variance analysis for comparison of groups. Categorical variables are presented as number and percentage, and the $\chi^{2}$ test was used for comparison of groups. The Kaplan-Meier method was used to calculate the cumulative incidence of CVEs in all subgroups. The log-rank test was used to determine whether a significant difference was present in the incidence of CVEs in different groups within the same BMI group. A Cox proportional hazard regression model was used to assess the risk of CVEs in relation to $A R V_{\mathrm{SBP}}$ in the same and different BMI groups. We used a competitive risk model for a second risk assessment of CVEs in relation to $\mathrm{ARV}_{\mathrm{SBP}}$ in different $\mathrm{BMI}$ groups, taking into account the effect of death in the Cox risk model. A sensitivity analysis was used to separately analyse patients with hypertension (SBP of $>140 \mathrm{~mm} \mathrm{Hg}$

\begin{tabular}{llllllll}
\hline \multicolumn{7}{l}{ Table 2} & \multicolumn{7}{l}{ Cumulative incidence of CVEs in the ARV } \\
\hline SBP & subgroups within the same BMI group & & \\
\hline Group & & Total & Q1 & Q2 & Q3 & Q4 & Log-rank \\
\hline BMl<24.0 & No. of case (\%) & $273(1.68)$ & $30(0.73)$ & $54(1.34)$ & $69(1.70)$ & $120(2.96)$ & $<0.001$ \\
$24.0 \leq B M l>28.0$ & No. of case (\%) & $387(2.25)$ & $68(1.60)$ & $85(1.95)$ & $89(2.04)$ & $145(3.41)$ & $<0.001$ \\
BMl $\geq 28$ & No. of case (\%) & $208(2.74)$ & $41(2.16)$ & $39(2.04)$ & $55(2.92)$ & $73(3.84)$ & 0.001 \\
Log-rank & - & $<0.001$ & $<0.001$ & 0.04 & 0.002 & 0.09 & -
\end{tabular}

$\mathrm{ARV}_{\mathrm{SBP}}$, average real variability of systolic blood pressure; BMI, body mass index; CVEs, cardiovascular events. 
Table 3 Risk assessment of CVEs in relation to $\mathrm{ARV}_{\mathrm{SBP}}$ in the same BMI groups

\begin{tabular}{|c|c|c|c|c|c|c|}
\hline Group & $\mathrm{ARV}_{\mathrm{SBP}}$ & $\begin{array}{l}\text { No. of } \\
\text { cases }\end{array}$ & $\begin{array}{l}\text { Person- } \\
\text { years }\end{array}$ & $\begin{array}{l}\text { Model1 } \\
\text { HR }(95 \% \mathrm{Cl})\end{array}$ & $\begin{array}{l}\text { Model } 2 \\
\text { HR }(95 \% \mathrm{Cl})\end{array}$ & $\begin{array}{l}\text { Competitive risk } \\
\text { model } \\
\text { HR }(95 \% \mathrm{Cl})\end{array}$ \\
\hline \multirow[t]{4}{*}{$\mathrm{BMI}<24.0$} & Q1 & 30 & 15653 & 1 (Reference) & 1 (Reference) & 1 (Reference) \\
\hline & Q2 & 54 & 15246 & 1.64 (1.05 to 2.56$)$ & 1.62 (1.03 to 2.53 ) & $1.60(1.02$ to 2.50$)$ \\
\hline & Q3 & 69 & 15164 & 1.89 (1.23 to 2.91$)$ & 1.77 (1.15 to 2.72$)$ & 1.73 (1.12 to 2.68$)$ \\
\hline & Q4 & 120 & 14766 & 2.88 (1.92 to 4.33$)$ & 2.20 (1.46 to 3.31$)$ & 2.10 (1.37 to 3.22$)$ \\
\hline $\mathrm{P}$ trend & - & - & - & $<0.001$ & $<0.001$ & - \\
\hline \multirow[t]{4}{*}{$24.0 \leq \mathrm{BMl}>28.0$} & Q1 & 68 & 16279 & 1 (Reference) & 1 (Reference) & 1 (Reference) \\
\hline & Q2 & 85 & 16505 & 1.13 (0.82 to 1.56$)$ & 1.06 (0.77 to 1.47$)$ & 1.06 (0.76 to 1.46$)$ \\
\hline & Q3 & 89 & 16352 & 1.11 (0.81 to 1.52$)$ & 0.98 (0.70 to 1.34$)$ & 0.97 (0.70 to 1.35$)$ \\
\hline & Q4 & 145 & 15579 & 1.65 (1.23 to 2.22$)$ & 1.18 (0.86 to 1.61$)$ & 1.17 (0.85 to 1.61$)$ \\
\hline $\mathrm{P}$ trend & - & - & - & 0.001 & 0.36 & - \\
\hline \multirow[t]{4}{*}{$\mathrm{BMI} \geq 28.0$} & Q1 & 41 & 7279 & 1 (Reference) & 1 (Reference) & 1 (Reference) \\
\hline & Q2 & 39 & 7256 & 0.89 (0.57 to 1.38$)$ & 0.84 (0.54 to 1.32$)$ & 0.84 (0.54 to 1.32$)$ \\
\hline & Q3 & 55 & 7043 & 1.23 (0.82 to 1.85$)$ & 1.12 (0.74 to 1.70$)$ & 1.12 (0.73 to 1.70$)$ \\
\hline & Q4 & 73 & 6970 & 1.47 (0.99 to 2.17$)$ & 1.17 (0.78 to 1.77$)$ & $1.17(0.76$ to 1.80$)$ \\
\hline $\mathrm{P}$ trend & - & - & - & 0.015 & 0.23 & - \\
\hline
\end{tabular}

Model 1: adjusted for age and sex; Model 2 and Competition model: adjusted for sex, age, total cholesterol level, heart rate, high-sensitivity C reactive protein, high-density lipoprotein level, sbp1, smoking, salt intake, drinking, exercise and diabetes mellitus.

$\mathrm{ARV}_{\mathrm{SBP}}$, average real variability of systolic blood pressure; BMI, body mass index; CVEs, cardiovascular events; sbp1, systolic blood pressure of the first physical examination.

or diastolic BP of $>90 \mathrm{~mm} \mathrm{Hg}$ or receiving antihypertensive therapy) and those with antihypertensive therapy in the four medical examinations because of the potential influence of hypertension and antihypertensive therapy on CVEs and BPV. ${ }^{26}{ }^{27} \mathrm{~A}$ two-sided $\mathrm{p}<0.05$ was considered statistically significant.

\section{RESULTS}

A total of 59008 participants underwent the first physical examination, of whom 41043 were included in the final analysis after exclusion for the following reasons. We excluded 3330 participants with previous CVEs, 330 with a history of tumours, and 1439 with incomplete or missing data regarding height or weight in the first physical examination. Among the remaining 53909 participants, we further excluded 5941 with incidence of CVEs, 2248 with a tumour and 2259 who died during the four examinations. We also excluded 2418 with any missing SBP data. Among the final participants, 31231 (76.1\%) were men and their mean age was $47.6 \pm 11.4$ years. The mean follow-up time was $3.75 \pm 0.54$ years.

\section{Participants' general information}

Increases in BMI were associated with increases in the mean or proportion of the total cholesterol level, salt intake, diabetes mellitus, hypertension, antihypertensive therapy, snoring, $\mathrm{SBP}$ of the four examinations, $\mathrm{ARV}_{\mathrm{SBP}}$ and high-sensitivity $\mathrm{C}$ reactive protein level $(\mathrm{p}<0.05)$. The overweight group had the highest rates of older age, male sex, smoking, physical exercise and drinking (table 1).

\section{Cumulative incidence of CVEs in relation to visit-to-visit BPV in different BMI groups}

During the mean follow-up of $3.75 \pm 0.54$ years, 868 CVEs occurred. As the BMI increased, the cumulative incidence of CVEs gradually but significantly increased $(p<0.05)$. In the normal weight and overweight groups, as the $\mathrm{ARV}_{\mathrm{SBP}}$ increased, the cumulative incidence of CVEs gradually increased $(p<0.05)$. The cumulative incidence of CVEs gradually increased from $\mathrm{Q} 2$ to $\mathrm{Q} 4$ in the obesity group $(p<0.05)$. Except for $Q 4$, the cumulative incidence of CVEs significantly increased as the BMI increased within the same $\mathrm{ARV}_{\mathrm{SBP}}$ subgroup $(\mathrm{p}<0.05)$ (table 2$)$.

Cox proportional hazard regression model for risk assessment of CVEs in relation to visit-to-visit BPV in BMI groups

The incidence of CVEs was the dependent variable, $\mathrm{ARV}_{\mathrm{SBP}}$ was the independent variable and $\mathrm{Q} 1$ of the normal weight group served as the control group ( $p$ for interaction $<0.05)$. After adjusting for confounding factors, the risk of CVEs in the $\mathrm{ARV}_{\mathrm{SBP}}$ subgroups within each BMI group was higher than that in Q1 of $\mathrm{ARV}_{\mathrm{SBP}}$ in the normal weight group $(\mathrm{p}<0.05)$. The risk of $Q 4$ in the obesity group was the highest at 2.28 times. In the overweight and obesity groups, however, the HR did not seem to vary substantially as the $\mathrm{ARV}_{\mathrm{SBP}}$ increased (figure 1 ). 
Table 4 Cox analysis of ARV ${ }_{S B P}$ in CVEs in different participants in the same BMI groups

\begin{tabular}{|c|c|c|c|c|c|c|c|}
\hline \multirow[b]{2}{*}{ Group } & \multirow[b]{2}{*}{$\mathrm{ARV}_{\mathrm{SBP}}$} & \multicolumn{3}{|c|}{ Excluding person with hypertension } & \multicolumn{3}{|c|}{$\begin{array}{l}\text { Excluding person on antihypertensive } \\
\text { therapy }\end{array}$} \\
\hline & & $\begin{array}{l}\text { No. of } \\
\text { cases }\end{array}$ & $\begin{array}{l}\text { Person- } \\
\text { years }\end{array}$ & $\begin{array}{l}\text { Model } \\
\text { HR (95\% Cl) }\end{array}$ & $\begin{array}{l}\text { No. of } \\
\text { cases }\end{array}$ & $\begin{array}{l}\text { Person- } \\
\text { years }\end{array}$ & $\begin{array}{l}\text { Model } \\
\text { HR (95\% Cl) }\end{array}$ \\
\hline \multirow[t]{4}{*}{$\mathrm{BMl}<24$} & Q1 & 20 & 10251 & 1 (Reference) & 23 & 13855 & 1 (Reference) \\
\hline & Q2 & 24 & 10909 & 1.09 (0.60 to 1.99$)$ & 42 & 13476 & 1.65 (0.99 to 2.75$)$ \\
\hline & Q3 & 44 & 10704 & $1.84(1.08$ to 3.14$)$ & 47 & 13588 & 1.55 (0.94 to 2.57$)$ \\
\hline & Q4 & 59 & 10300 & 1.99 (1.18 to 3.35$)$ & 83 & 13221 & 2.02 (1.25 to 3.26$)$ \\
\hline$P$ trend & & & & 0.002 & & & 0.008 \\
\hline \multirow[t]{4}{*}{$24.0 \leq \mathrm{BMl}>28.0$} & Q1 & 26 & 8414 & 1 (Reference) & 45 & 13045 & 1 (Reference) \\
\hline & Q2 & 26 & 8477 & 1.03 (0.59 to 1.78$)$ & 45 & 12954 & 0.84 (0.55 to 1.28$)$ \\
\hline & Q3 & 38 & 8646 & 1.25 (0.75 to 2.08$)$ & 56 & 12866 & 0.98 (0.66 to 1.45$)$ \\
\hline & Q4 & 45 & 8271 & 1.32 (0.80 to 2.17$)$ & 86 & 12498 & $1.13(0.77$ to 1.66$)$ \\
\hline $\mathrm{P}$ trend & & & & 0.20 & & & 0.33 \\
\hline \multirow[t]{4}{*}{$\mathrm{BMI} \geq 28$} & Q1 & 12 & 3178 & 1 (Reference) & 20 & 5162 & 1 (Reference) \\
\hline & Q2 & 14 & 2930 & 1.16 (0.53 to 2.53$)$ & 24 & 5139 & 1.07 (0.59 to 1.95$)$ \\
\hline & Q3 & 17 & 2603 & 1.68 (0.73 to 3.56$)$ & 34 & 5097 & 1.33 (0.76 to 2.32 ) \\
\hline & Q4 & 20 & 2864 & 1.86 (0.88 to 3.94$)$ & 40 & 4979 & 1.40 (0.80 to 2.45$)$ \\
\hline $\mathrm{P}$ trend & & & & 0.06 & & & 0.17 \\
\hline
\end{tabular}

The model was adjusted for sex, age, total cholesterol level, heart rate, high-sensitivity $\mathrm{C}$ reactive protein level, high-density lipoprotein level, sbp1, smoking, salt intake, drinking, exercise and diabetes mellitus.

$\mathrm{ARV}_{\mathrm{SBP}}$, average real variability of systolic blood pressure; BMI, body mass index; CVEs, cardiovascular events; sbp1, systolic blood pressure of the first physical examination.;

The incidence of CVEs was the dependent variable, $\mathrm{ARV}_{\mathrm{SBP}}$ was the independent variable, and the $\mathrm{Q} 1$ group of $\mathrm{ARV}_{\mathrm{SBP}}$ served as the reference group in the same BMI group ( $\mathrm{p}$ for interaction $<0.05$ ). After adjusting for confounding factors, as $\mathrm{ARV}_{\mathrm{SBP}}$ increased, the risk of CVEs showed an increasing trend in the normal weight group $(\mathrm{p}<0.05)$, and the risk in the Q4 group was 2.20 times that in the Q1 group. In the overweight and obesity groups, there was no significant risk of CVEs with an increase in $\mathrm{ARV}_{\mathrm{SBP}}$ (table 3).

In total, 961 deaths occurred during the follow-up period. The incidence of CVEs was the dependent variable, $\mathrm{ARV}_{\mathrm{SBP}}$ was the independent variable and the $\mathrm{Q} 1$ group of $A R V_{S B P}$ in each BMI group served as the reference group. The effect of $\mathrm{ARV}_{\mathrm{SBP}}$ on CVEs in the same BMI group remained unchanged. However, the risk was slightly lower than that in the previous Cox model (table 3).

\section{Sensitivity analysis}

Participants undergoing hypertensive and antihypertensive therapy were excluded, and a sensitivity analysis was then performed after adjusting for confounding factors. In the normal weight group, the risk of CVEs in Q3 and Q4 was still higher than that in Q1, although the risk was slightly lower than that in all participants. However, Q2 was not significant. This risk also tended to increase as $\mathrm{ARV}_{\mathrm{SBP}}$ increased. However, the results had no statistical significance in the overweight and obesity groups (table 4).

\section{DISCUSSION}

This study is the first to show that compared with the Q1 group of $\mathrm{ARV}_{\mathrm{SBP}}$ in the normal weight group, the risk of CVEs significantly increased as the BMI and $\mathrm{ARV}_{\mathrm{SBP}}$ increased. However, there were comparatively few variations in the overweight and obesity groups. In addition, we found that visit-to-visit BPV has different effects on CVEs in different BMI groups. The risk of CVEs increased with increasing $\mathrm{ARV}_{\mathrm{SBP}}$ only in the normal weight group.

We found that the risk of CVEs in relation to $A R V_{\text {SBP }}$ in each BMI group was significantly higher than that in Q1 of the normal weight group with an increase in BMI and $\mathrm{ARV}_{\mathrm{SBP}}$. This finding indicates that in different BMI groups, the risk of CVEs increased as $\mathrm{ARV}_{\mathrm{SBP}}$ rose. However, there was no obvious change in the gradient, which indicated the significance of the $\mathrm{ARV}_{\mathrm{SBP}}$ subgroups in various BMI groups. This finding also suggests that prediction of the risk of CVEs using $\mathrm{ARV}_{\mathrm{SBP}}$ mainly depended on the $\mathrm{BMI}$ and that the predictive value of $\mathrm{ARV}_{\mathrm{SBP}}$ was higher in the lower-weight groups. Furthermore, a higher BMI was associated with a greater effect of $\mathrm{ARV}_{\mathrm{SBP}}$ on the risk of CVEs. The reason for these findings may be that the BMI and $A R V_{S B P}$ were risk factors for CVEs, and the interaction 
(as a protective factor) between the $\mathrm{BMI}$ and $\mathrm{ARV}_{\mathrm{SBP}}$ reduced the effect of $A R V_{S B P}$ on CVEs.

We found that the incidence of CVEs increased as the $\mathrm{ARV}_{\mathrm{SBP}}$ increased in the normal and overweight groups. However, the risk of CVEs caused by an increase in $\mathrm{ARV}_{\mathrm{SBP}}$ was meaningful only in the normal weight group (among the subgroups of $\mathrm{ARV}_{\mathrm{SBP}}$ in the normal weight group, the risk of CVEs of Q4 was increased 2.20 times compared with Q1). Our results compensate for the lack of previous studies. Previous cohort studies and meta-analyses ${ }^{6-8}$ showed that visit-to-visit BPV was a risk factor for CVEs, but they did not consider BMI and $\mathrm{ARV}_{\mathrm{SBP}}$ as risk factors or the interaction between them. Our previous study also showed that $\mathrm{ARV}_{\mathrm{SBP}}$ increased as the $\mathrm{BMI}$ increased; Visitto-visit BPV was also a risk factor for CVEs. ${ }^{48}$

Why an increased risk of CVEs was related to an increase in $\mathrm{ARV}_{\mathrm{SBP}}$ only in the normal weight group is unclear. The mechanism of this finding remains to be investigated, but we consider that the effect of smoking cannot be ignored. A previous study showed that smokers have a low BMI and high BPV. ${ }^{29}{ }^{30}$ After adjusting for smoking in our study, $\mathrm{ARV}_{\mathrm{SBP}}$ was still a risk factor in the normal weight group, which supports the conclusion of this study. Additionally, in the overweight and obesity groups, a high BMI was a risk factor for CVEs, together with a higher level or proportion of risk factors such as SBP, cholesterol and diabetes mellitus. These findings weaken the predictive meaning of $\mathrm{ARV}_{\mathrm{SBP}}$ in the risk of CVEs. Another important point is that participants in the normal weight group tended to be younger and have a lower incidence of BP therapy. However, participants with a higher BMI were more likely to be older and hypertensive and to be undergoing $\mathrm{BP}$ therapy.

Because of the effect of death on the Cox risk model, we chose a competitive risk model analysis to re-estimate the effect of $\mathrm{ARV}_{\mathrm{SBP}}$ on CVEs in the same BMI group. We found that the effect of $A R V_{\mathrm{SBP}}$ in the same BMI group on CVEs did not change; however, the risk was slightly lower than that in the original Cox model. The competitive risk model more realistically reflected the effect of $\mathrm{ARV}_{\mathrm{SBP}}$ on CVEs in the same BMI group on CVEs, and the effect of $A R V_{S B P}$ on CVEs in the same BMI group remained significant. Considering the possibility that hypertension and antihypertensive therapy may affect the results of our study, a sensitivity analysis was performed after eliminating these two factors. In the normal weight group, the effect of $\mathrm{ARV}_{\mathrm{SBP}}$ on CVEs in all subgroups (except Q2) remained unchanged, with the risk slightly lower than that in the previous Cox model. This may have occurred because the lower SBP and BPV in the population with normal $\mathrm{BP}$ weakened the prediction of $\mathrm{ARV}_{\mathrm{SBP}}$ on CVEs. This finding may have also been due to the fact that participants with hypertension or undergoing antihypertensive therapy were data-processed and might have had lesions of the related target organ, increasing the risk of CVEs.

This study has two major strengths. First, a competitive risk model was adopted for the second risk assessment to more accurately estimate the risk of CVEs. Second, this study is important for clinical and public health. It may allow clinicians to recommend that people who are overweight or obese lose weight and prevent CVEs by controlling BP and BPV. For people of normal weight with hypertension, clinicians may advise against obesity and should pay more attention to the BPV while controlling BP.

This study also has some limitations. First, the research population was limited to Kailuan Group employees, most of whom lived in communities in North China. Thus, the findings of this study may not be applicable to other populations. Nevertheless, the homogeneity of our cohort reduced the potential confounders, and the large sample size of the study is highly instructive for the Chinese population. Second, measurements of BP were only obtained from physical examination data; no information on home BP or multiple BP measurements in 1 year was collected. However, the BP measurements in this study spanned 8 years, with a total of four measurement times, and BP was still a significant predictor of CVEs. Third, the large proportion of men in this study may have affected the prediction of CVEs. However, the average age of the study population was 47.6 years; thus, the effect of sex on the incidence of CVEs was weak.

\section{CONCLUSION}

$\mathrm{BMI}$ and $\mathrm{ARV}_{\mathrm{SBP}}$ are risk factors for CVEs. As BMI and $\mathrm{ARV}_{\mathrm{SBP}}$ increase, the risk of CVEs increases accordingly. However, the effect of visit-to-visit BPV on the risk of CVEs mainly varies in different BMI groups, especially in the normal weight group.

\section{Author affiliations}

${ }^{1}$ Cardiology, First Hospital of Medical College of Shantou University, Shantou, Guangdong, China

${ }^{2}$ Cardiology, Shantou University Medical College, Shantou, Guangdong, China ${ }^{3}$ Cardiology, Second Affiliated Hospital of Shantou University Medical College, Shantou, Guangdong, China

${ }^{4}$ Foreign Language, Guangdong Polytechnic Normal University, Guangzhou, Guangdong, China

${ }^{5}$ Department of Cardiology, Kailuan General Hospital, Tangshan, Hebei, China

\section{Twitter Jianhuan Huang @No}

Acknowledgements We sincerely express our gratitude to all parties in the Kailuan Study, as well as members of Kailuan General Hospital and its affiliated hospitals.

Contributors $\mathrm{HC}$, SW and YC take responsibility for all aspects of the reliability and freedom from bias of the data presented and their discussed interpretation. $\mathrm{HC}$ and $\mathrm{JH}$ carried out the statistical analysis. ZKC, WW and ZCC participated in the study design. XY and SW strictly reviewed the manuscript. All of the authors read and approved the final draft of the manuscript.

Funding This work was supported by the National Natural Science Foundation of China (No. 81870312).

Competing interests None declared.

Patient consent for publication Not required.

Ethics approval This study was in accordance with the Helsinki Declaration and approved by the Ethics Committee of Kailuan General Hospital, and the written informed consents signed by all individuals in the observation group. 
Provenance and peer review Not commissioned; externally peer reviewed.

Data availability statement Data are available on reasonable request. Datasets that were generated and analysed in this study will not be published because of data protection, but the appropriate authors may have access to and/or analyse the datasets of the current study if reasonably required.

Open access This is an open access article distributed in accordance with the Creative Commons Attribution Non Commercial (CC BY-NC 4.0) license, which permits others to distribute, remix, adapt, build upon this work non-commercially, and license their derivative works on different terms, provided the original work is properly cited, appropriate credit is given, any changes made indicated, and the use is non-commercial. See: http://creativecommons.org/licenses/by-nc/4.0/.

ORCID iDs

Haojia Chen http://orcid.org/0000-0001-7310-2778

Youren Chen http://orcid.org/0000-0002-4060-3725

\section{REFERENCES}

$1 \mathrm{Ng} \mathrm{M}$, Fleming T, Robinson M, et al. Global, regional, and national prevalence of overweight and obesity in children and adults during 1980-2013: a systematic analysis for the global burden of disease study 2013. Lancet 2014;384:766-81.

2 Friedrich MJ. Assessing and addressing global malnutrition. J Am Med Assoc 2015;313.

3 Li Z, Snieder H, Su S, et al. A longitudinal study of blood pressure variability in African-American and European American youth. $J$ Hypertens 2010;28:715-22.

4 Chen $\mathrm{H}$, Zhang $\mathrm{R}$, Zheng $\mathrm{Q}$, et al. Impact of body mass index on long-term blood pressure variability: a cross-sectional study in a cohort of Chinese adults. BMC Public Health 2018;18:1193.

5 Brunner EJ, Shipley MJ, Ahmadi-Abhari S, et al. Adiposity, obesity, and arterial aging: longitudinal study of aortic stiffness in the Whitehall II cohort. Hypertension 2015;66:294-300.

6 Murray CJL, Vos T, Lozano R, et al. Disability-adjusted life years (DALYs) for 291 diseases and injuries in 21 regions, 1990-2010: a systematic analysis for the global burden of disease study 2010. Lancet 2012;380:2197-223.

7 Global Burden of Metabolic Risk Factors for Chronic Diseases Collaboration (BMI Mediated Effects), Lu Y, Hajifathalian K, et al. Metabolic mediators of the effects of body-mass index, overweight, and obesity on coronary heart disease and stroke: a pooled analysis of 97 prospective cohorts with 1.8 million participants. Lancet 2014;383:970-83

8 Stevens SL, Wood S, Koshiaris C, et al. Blood pressure variability and cardiovascular disease: systematic review and meta-analysis. BMJ 2016;354:i4098.

9 Wilson PWF, D'Agostino RB, Sullivan L, et al. Overweight and obesity as determinants of cardiovascular risk: the Framingham experience. Arch Intern Med 2002;162:1867-72.

10 Wu S, Huang Z, Yang X, et al. Prevalence of ideal cardiovascular health and its relationship with the 4-year cardiovascular events in a northern Chinese industrial City. Circ Cardiovasc Qual Outcomes 2012;5:487-93.

11 Jin C, Chen S, Vaidya A, et al. Longitudinal change in fasting blood glucose and myocardial infarction risk in a population without diabetes. Diabetes Care 2017;40:1565-72.

12 Sega R, Cesana G, Bombelli M, et al. Seasonal variations in home and ambulatory blood pressure in the PAMELA population.
Pressione Arteriose Monitorate E Loro Associazioni. J Hypertens 1998;16:1585-92.

13 Wu C, Shlipak MG, Stawski RS, et al. Visit-to-Visit blood pressure variability and mortality and cardiovascular outcomes among older adults: the health, aging, and body composition study. Am J Hypertens 2017;30:151-8.

14 Gao S, Hendrie HC, Wang C, et al. Redefined blood pressure variability measure and its association with mortality in elderly primary care patients. Hypertension 2014;64:45-52.

15 Suchy-Dicey AM, Wallace ER, Mitchell SVE, et al. Blood pressure variability and the risk of all-cause mortality, incident myocardial infarction, and incident stroke in the cardiovascular health study. Am J Hypertens 2013;26:1210-7.

16 Shimbo D, Newman JD, Aragaki AK, et al. Association between annual visit-to-visit blood pressure variability and stroke in postmenopausal women: data from the women's health Initiative. Hypertension 2012;60:625-30.

17 Zakopoulos NA, Tsivgoulis G, Barlas G, et al. Time rate of blood pressure variation is associated with increased common carotid artery intima-media thickness. Hypertension 2005;45:505-12.

18 Mena L, Pintos S, Queipo NV, et al. A reliable index for the prognostic significance of blood pressure variability. $J$ Hypertens 2005;23:505-11.

19 Hastie CE, Jeemon $\mathrm{P}$, Coleman $\mathrm{H}$, et al. Long-Term and ultra longterm blood pressure variability during follow-up and mortality in 14,522 patients with hypertension. Hypertension 2013;62:698-705.

20 Mena LJ, Felix VG, Melgarejo JD, et al. 24-Hour blood pressure variability assessed by average real variability: a systematic review and meta-analysis. J Am Heart Assoc 2017;6:e006895.

21 Rothwell PM, Howard SC, Dolan E, et al. Prognostic significance of visit-to-visit variability, maximum systolic blood pressure, and episodic hypertension. Lancet 2010;375:895-905

22 Filomena J, Riba-Llena I, Vinyoles E, et al. Short-Term blood pressure variability relates to the presence of subclinical brain small vessel disease in primary hypertension. Hypertension 2015;66:634-40.

23 Manisty $\mathrm{CH}$, Hughes AD. Meta-Analysis of the comparative effects of different classes of antihypertensive agents on brachial and central systolic blood pressure, and augmentation index. $\mathrm{Br} \mathrm{J}$ Clin Pharmacol 2013;75:79-92.

24 Mahmud A, Feely J. Favourable effects on arterial wave reflection and pulse pressure amplification of adding angiotensin II receptor blockade in resistant hypertension. J Hum Hypertens 2000;14:541-6.

25 Zhou B. Coorperative meta-analysis group of China obesity Task force. Predictive values of body mass index and waist circumference to risk factors of related diseases in Chinese adult population 2002;23:5-10.

26 Rothwell PM, Howard SC, Dolan E, et al. Effects of beta blockers and calcium-channel blockers on within-individual variability in blood pressure and risk of stroke. Lancet Neurol 2010;9:469-80.

27 Webb AJS, Fischer U, Mehta Z, et al. Effects of antihypertensivedrug class on interindividual variation in blood pressure and risk of stroke: a systematic review and meta-analysis. Lancet 2010;375:906-15.

28 Dai L, Song L, Li X, et al. Association of visit-to-visit blood pressure variability with the risk of all-cause mortality and cardiovascular events in general population. J Clin Hypertens 2018;20:280-8.

29 Tian J, Venn A, Otahal P, et al. The association between quitting smoking and weight gain: a systematic review and meta-analysis of prospective cohort studies. Obes Rev 2015;16:883-901.

30 Ragueneau I, Michaud P, Démolis JL, et al. Effects of cigarette smoking on short-term variability of blood pressure in smoking and non smoking healthy volunteers. Fundam Clin Pharmacol 1999;13:501-7. 